Books, videos, cd-roms, dvds and any other relevant items submitted for a review in the BDJ should be addressed to:

Mike Grace, Editor, British Dental Journal, 64 Wimpole Street W1G 8YS

\section{Periodontal Management of Children, Adolescents and Young Adults}

\author{
V. Clerehugh, A. Tugnait, I.L.C. Chapple \\ Surrey: Quintessence, 2004 \\ price £28, pp187 \\ ISBN 1850970718
}

In general this book provides a succinct guide to the diagnosis and management of the periodontal diseases and conditions that can affect children and young people. In particular, it emphasises a practical approach aimed at helping a general dental practitioner provide appropriate periodontal care for this age range. However, it also provides clear indications of when referral to a consultant or specialist should be considered.

The book starts by dispelling the myth that periodontitis rarely occurs before 30 years of age. The first two chapters deal briefly with the relevant anatomy, epidemiology and current views on the pathogenic mechanisms of periodontal disease in this age group. The classification system for periodontal diseases used by most current publications is described briefly.

Chapters three to five provide up to date advice about obtaining relevant histories, identifying risk factors for periodontal disease, examination and periodontal diagnosis appropriate to young patients. In particular, they describe an approach to periodontal screening for this age group that indicates when a comprehensive periodontal examination needs to occur. Taken together with the identification of relevant systemic and local risk factors for disease, the reader is then lead through the possible periodontal diagnoses illustrated by clear clinical photographs, radiographs and diagrams.

The following two chapters cover nonplaque induced periodontal conditions, some of which are relatively common, others very rare, and some are manifestations of life-threatening medical
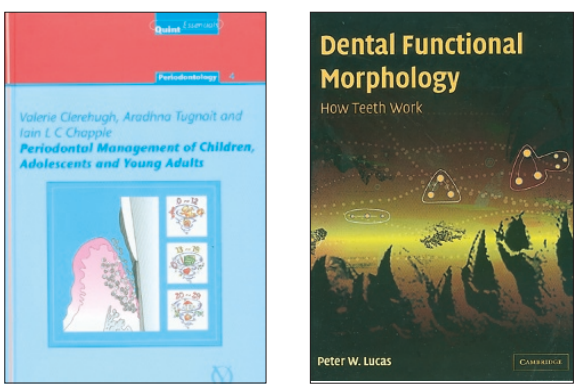

conditions. This section could provide the general practitioner with a simple reference book to help recognise conditions infrequently encountered but with significant consequences for the patient if not recognised and referred appropriately.

The final three chapters concentrate on the delivery of treatment from the perspective of the dental team including the general dentist, hygienist and specialist practitioner. Sensible, practical advice about communication with and motivation of children, adolescents and young adults is included. The general practitioner is encouraged to provide initial periodontal therapy for plaquerelated diseases before considering referral or after referral while the patient awaits an appointment with a specialist. In addition, the crucial role of the general practice team in helping to maintain the results of periodontal therapy is also stressed.

This book should help practitioners recognise and deal appropriately with the range of periodontal conditions seen in young patients.

V. Booth

\title{
Dental Functional Morphology: How Teeth Work
}

\section{P.W. Lucas \\ Cambridge: Cambridge University Press, 2004 price $€ 75$, pp355 \\ ISBN 0521562368}

It is always quite exciting receiving a book to review, especially one where you know nothing about the author. After reading this book you come away feeling you actually know quite a lot about the author and his character, thoughts and beliefs. Professor Lucas has written a very personal book on a subject about which he clearly feels quite passionate. It is a very well written text and covers a great deal of ground. The topic is not one that instantly springs to mind as an area for significant undergraduate or postgraduate study. It is a specific area and the book deals - as the author quite rightly states - with the mouth as an oral food processor. The preface is well worth a read as it allows the author to open his heart and explain why he wrote the book. The book is not really aimed at the practising dentist, but at anyone who may have an interest in the function of teeth. It also gives a well researched, but personal, view of the evolution of teeth relative to function. The author's style is very chatty and his sense of humour pervades the whole text making the book very readable.

The first chapter gives a nice introduction to the coming chapters; two to five then look at the structure and function of the mammalian mouth including relevant comment on the evolution of other dentitions relative to function. Fracture mechanics is a major part of the author's thinking regarding the function of teeth. A flick-art placed in the corner of the book allows a very rapid appreciation of the change in shape of teeth over time, complementing the text and its succinct explanations of the same. The final chapter ends with another thought-provoking statement that mastication is a unique major motor activity of mammals and yet little is written about it in a comprehensive manner. The author, successfully in my opinion, attempts to correct this imbalance.

The book contains long appendices, the first giving a very effective explanation of mechanical properties and their measurement. There is also a notes section providing additional information on the chapter contents.

This book will not make the essential reading list of undergraduate programmes in dentistry. It is perhaps more relevant to undergraduate food scientists and nutritionists. It is not a standard postgraduate text except for those highly motivated and interested in this aspect of teeth.

M.J. Woolford 